\title{
Production and verification of human papillomavirus type 18 vaccine in vitro
}

\author{
SHUJIE LIAO*, SHIXUAN WANG* , LING XU, DONGRUI DENG, QIAN XU, WEI WANG, TAO ZHU, \\ XIANGYANG BAI, JIANFENG ZHOU, GANG XU, YUNPING LU, LI MENG and DING MA \\ Cancer Biology Research Center, Tongji Hospital, Tongji Medical College, Huazhong \\ University of Science and Technology, Wuhan, Hubei 430030, P.R. China
}

Received December 7, 2007; Accepted February 27, 2008

\begin{abstract}
This study aimed to generate human papillomavirus (HPV) type 18 L1 virus-like particles (VLPs) and investigated the immunity effectiveness in vitro by using the Bac to Bac baculovirus expression system and Ni-NTA purification system to express and purify the VLP. The bio-function and immune response of purified VLP were analyzed by a mouse erythrocyte haemagglutination assay and the IFN- $\gamma$ ELISPOT. The proteins of interest, primarily located at the nucleus, formed VLP by self-assembly, and had an effective immune activity in vitro. The level of IFN- $\gamma$ in the specific HPV18 positive group was significantly higher than that of the mixed high-risk HPV infected group and non-HPV infection one in vitro. Our study indicated that HPV18 later protein L1 was efficiently expressed in Bac to Bac baculovirus expression system and the HPV18 L1-VLPs showed immunoreactivity and bio-activity in vitro. Furthermore, the ELISPOT results support the hypothesis that the cell-mediated immunity generated by HPV18 L1-VLP may cross-type among highrisk HPV types.
\end{abstract}

\section{Introduction}

Human papillomavirus (HPVs) belongs to the papillomavavirus family, and $>120$ human types are verified thus far.

Correspondence to: Dr Ding Ma, Cancer Biology Center, Tongji Hospital, Tongji Medical College, Huazhong University of Science and Technology, 1095 Jiefang Avenue, Wuhan, Hubei 430030, P.R. China

E-mail:dingma424@yahoo.com,dma@tjh.tjmu.edu.cn

${ }^{*}$ Contributed equally

Abbreviations: HPV, human papillomavirus; IL-2, interleukin-2; IFN- $\gamma$, interferon- $\gamma$; ELISPOT, enzyme-linked immunospot; SDSPAGE, sodium dodecyl sulphate-polyacrylamide gel; CTL, cytotoxic T lymphocyte; PBMCs, peripheral blood mononuclear cells

Key words: human papillomavirus type 18, Bac to Bac baculovirus expression system, virus-like particles, enzyme-linked immunospot
HPVs are specific for the infection of epithelial cells, including those in the skin, respiratory mucosa and genital tract (1). HPV has been shown to be the etiological agent of many cancers, and persistent infections of HPV types with a high carcinogenic potential are associated with many malignant diseases including head and neck squamous cell carcinomas, esophageal carcinoma, lung cancer, bladder carcinoma as well as genital cancers, especially the development of cervical cancer (2). However, besides surgery and chemotherapy, no specific treatment against HPV infection is available. With the development of molecular biology and immunology, a novel immunotherapy strategy that protects against HPV infection, directly and effectively, and reduces the HPV-related disease burden is needed urgently.

In 1991, Zhou et al (3) reported that the HPV16 L1 capsid protein was synthesized and could assemble by itself into DNA-free virus-like particles (VLPs) in vitro with a certain expression system. VLP is an icosahedral structure and the outer shell, or capsid, contains 72 pentamers, or capsomers of L1, the major capsid protein which has the same conformation epitope as homeotype HPV. VLP was able to induce a strong type-specific humoral response with neutralizing antibodies in vivo. The results suggested that VLP may be one of the best candidate immunogens for HPV vaccine trials.

The association between HPV infection and cervical cancer has been firmly established, and the oncogenic potential of certain HPV types has been demonstrated. Several lines of evidence suggest the importance of the host immune response, especially the cellular immune response, in the pathogenesis of HPV-associated cervical lesions. However, these observations form a compelling rationale for the development of vaccine therapy to combat HPV infection (4).

Many studies on HPV16 VLPs exist, but its bio-function and immune effect have received more and more attention in recent years. Although the second epidemic high-risk type HPV18 is associated with $20 \%$ HPV-related cervical cancer, research focusing on this aspect is rare. For a long time, we simply assumed HPV16 and 18 were the same. It is uncertain whether there is any difference between them or not. It is well-known that the HPV18 infection is related to cervical adenocarcinoma. HPV18 VLPs give knowledge of HPV18's biological characteristics as well as on the occurrence and development mechanisms of cervical adenocarcinoma. 
It is estimated that 493,000 new cases of invasive cervical cancer were diagnosed in $2002,83 \%$ of which were in developing countries, e.g. 150,000 new cases in China every year. At the same time, an estimated 273,000 deaths from cervical cancer occur worldwide each year, with over threefourths of them in developing countries $(5,6)$. However, the costly production and distribution of current VLP vaccines prevents widespread vaccine application in less developed countries. Consequently, due to the high demand in developing countries for the HPV vaccine, we are now producing an HPV prophylactic vaccine of HPV16, 18 and 58 based on L1 VLP. Herein we describe the generation of HPV18 VLPs in detail and demonstrate its functionality for vaccination purposes in vitro, which is fundamental to producing a preventive vaccine for future research.

\section{Materials and methods}

Cloning of HPV18 L1 and the construction of recombinant bacmid HPV18L1. The HPV18 L1 full-length gene was amplified by polymerase chain reaction (PCR) from plasmid PBR322-HPV18 including the complete gene of HPV18, which was kindly provided by Professor H. zur Hausen (Heidelberg University, Germany). PCR was performed using a high-fidelity DNA polymerase (Invitrogen, USA) in a $50 \mu 1$ reaction mixture with the primers: $\mathrm{L} 1$, forward $5^{\prime} \mathrm{CG} \underline{\mathrm{G}}$ AATTCAAATGTGCCTGTATACACGGGTC'3 and L1 reverse 5'CCCAAGCTTCACACATATTACTTCCTGG 3'. For these sequences, the EcoRI and HindIII restriction sites are underlined. The reaction conditions were: degeneration at $94^{\circ} \mathrm{C}$, $30 \mathrm{sec}$; annealing $52^{\circ} \mathrm{C}, 45 \mathrm{sec}$; extension $72^{\circ} \mathrm{C}, 60 \mathrm{sec}$ and 35 reaction cycles. The final PCR product was added with poly (A) tail and ligated to the T-easy vector (Promega, USA), producing the T-HPV18 L1 plasmid.

E. coli DH5a competent cells were transformed with ligation. Penicillin-resistant clones were screened for the presence of the L1 gene by PCR, restriction endonucleases were cleaved and the products electrophoresed in an ethidium bromide-stained $1 \%$ agarose gel. The correct sequence was confirmed by DNA sequencing (Invitrogen). Purified THPV18 L1 plasmid was cleaved with EcoRI and HindIII restriction endonucleases and ligated to the pFastBac Donor vector (Invitrogen), which was previously digested with EcoRI and HindIII, producing the pFastBac-HPV $18 \mathrm{~L} 1$ plasmid.

After the recombinant pFastBac donor plasmid was determined by DNA sequencing to be correct, the pFastBacHPV18 L1 was transformed into DH10BAC (containing bacmid and helper plasmid) for transposition into the bacmid. All transposition steps are according to the instruction manual.

PCR analysis of recombinant bacmid. PCR was carried out to confirm that the gene of interest had been transposed to the bacmid. The pUC/M13 amplification primers used in the study are directed at the sequences on either side of the miniatt $\operatorname{Tn} 7$ site within the lacZa-complementation region of the bacmid (7). If transposition has occurred, the size of the PCR product produced by these primers should be 2,300 bp plus the size of the insert. The primers were: sense, 5'GTTTTCCCAGTC ACGAC3' and anti-sense 5'CAGGAAACAGCTATGAC3'.
After incubation at $93^{\circ} \mathrm{C}$ for $3 \mathrm{~min}, 25-35$ cycles of PCR was performed as follows: $94^{\circ} \mathrm{C}$ for $45 \mathrm{sec}, 55^{\circ} \mathrm{C}$ for $45 \mathrm{sec}$ and $72^{\circ} \mathrm{C}$ for $5 \mathrm{~min}$.

Cell culture and the transfection of recombinant baculovirus. Monolayer cultures of Sf-9 cells (kindly provided by the Wuhan Institute of Virology Chinese Academy of Sciences, China) which were derived from pupal ovarian tissue of the fall armyworm, Spodoptera frugiperda, by Vaughn in 1977, using the packaging cells in the Bac to Bac baculovirus expression system, were grown at $27^{\circ} \mathrm{C}$ in Grace's insect medium supplemented with $10 \%$ fetal calf serum (Gibco/BRL, USA). The cells were transfected with recombinant bacmid HPV 18 L1 by Lipofectamine 2000 (Invitrogen) according to the manufacturer's recommendations. Viruses were harvested from the cell culture medium at $72 \mathrm{~h}$ post-transfection. Amplification of the viral stocks and viral plaque assay was carried out according to the instruction manual (7). The cells were infected at a multiplicity of infection (MOI) of 15-20 with the recombinant baculoviruses encoding the L1 protein. The cells were then collected at $48-72 \mathrm{~h}$ post-infection. The protein expression from isolated virus stocks was determined by Western blot analysis (see below).

SDS-PAGE electrophoresis and Western blot analysis. The cells were harvested $48-72 \mathrm{~h}$ after infection, lysed by boiling in SDS sample buffer and electrophoresed on $10 \%$ sodium dodecyl sulphate-polyacrylamide gel (SDS-PAGE). Proteins were stained with $0.25 \%$ Coomassie blue or transferred to a nitrocellulose membrane. The membrane was blocked for $1 \mathrm{~h}$ with $5 \%$ skim milk at $37^{\circ} \mathrm{C}$ and incubated with the $1: 500$ diluted monoclonal antibody anti-HPV18 L1 (Santa Cruz, USA) overnight at $4^{\circ} \mathrm{C}$. The secondary antibodies were then added at a 1:1000 dilution. The immunoreactive bands were visualized by the horseradish peroxidase ECL system (Amersham Pharmacia Biotech, Braunschweig, Germany) according to the manufacturer's instruction.

Purification of HPV18 L1 VLPs. HPV18 L1 VLPs were purified under native conditions with Ni-NTA His•Bind Resin (Novagen, Germany). All procedures followed the protocols in the Ni-NTA His•Bind Resin handbook. The infected cells were lysed, mixed with bind buffer and added to the Ni-NTA resin. After being bound, the lysates were washed three times with washing buffer to wash off the unbounded protein. Then the L1 protein was eluted with elute buffer. The purified VLPs were sterilized by filtering and made into protein powder for convenience of dilution.

Electron microscopy. Cells were prepared for electron microscopy as previously described (8). Briefly, cells (prepurification) were fixed in $2 \%$ paraformaldehyde $0.1 \%$ glutaraldehyde in PBS. After fixation, the cells were washed in Sabatini's solution and post-fixed with $1 \%$ osmium tetroxide. The samples were then passed through a graded alcohol series, infiltrated with acetone and embedded in Epon 812. Ultrathin $(60 \mathrm{~nm})$ sections were cut with a diamond knife on an MT2 Ultramicrotome (Sorvall), stained with uranyl acetate and lead citrate, mounted on 300-mesh grids and examined with a Philips electron microscope (EM, model EM 400T) (Royal 
Philips Electronics of The Netherlands). Preparation of the VLPs post-purified were almost the same as previously described (8).

Haemagglutination assay. The conformational intact VLPs can agglutinate mouse erythrocytes efficiently (9). Erythrocytes from C57BL/6 mice were drawn behind the eyeball, anticoagulated by heparin sodium and harvested by centrifugation. The erythrocytes were washed with PBS and resuspended at $1 \%(\mathrm{v} / \mathrm{v})$ in PBS containing $1 \mathrm{mg} / \mathrm{ml}$ bovine serum albumin (BSA). Serial dilutions of purified VLPs were prepared in PBS containing $1 \mathrm{mg} / \mathrm{ml} \mathrm{BSA}$ and mixed with an equal volume of a $1 \%(\mathrm{v} / \mathrm{v})$ suspension of erythrocytes in PBS. A $100 \mu 1$ aliquot of the mixture was added to each well of a 96-well plate. After incubation at $4^{\circ} \mathrm{C}$ for $3 \mathrm{~h}$, the plates were photographed. PBS containing $1 \mathrm{mg} / \mathrm{ml}$ BSA was regarded as the negative control and erythrocytes alone as the blank control (10).

IFN- $\gamma$ enzyme-linked immunospot (ELISPOT) assay, human subjects and isolation PBMCs. Blood samples were collected from 20 out-patients of the Department of Obstetrics and Gynecology of Tongji Hospital (affiliated to Tongji Medical College of Huazhong University of Science and Technology, China). The experimental protocols had previously been reviewed and approved by the Institute Review Boards of Tongji Hospital. Patients did not receive any treatment such as surgery, radiation or chemotherapy, except for cervical biopsy before the collection of PBMCs. The PBMCs were prepared with Ficoll-Paque solution (Amersham Biosciences, Uppsala, Sweden) for separation of the lymphocytes according to a method previously described (11). After centrifuging the blood/Ficoll-Paque gradients at $800 \mathrm{~g}$ for $30 \mathrm{~min}$, the layer containing the lymphocytes was transferred to another centrifuge tube and washed in PBS (12).

Detection and typing of the HPV genome. To confirm that HPV infection was present in the cervical keratinocytes, cervical cells were collected with a cervical brush and subjected to tests by the Hybrid Capture II system (Digene, USA) according to the manufacturer's instructions. After undergoing denature, hybridization, capture, detection and analysing, the samples which were infected with 13 high-risk HPV were obtained without HPV typing.

Individual HPV typing was confirmed by HPV DNA gene array. Briefly, hybridized arrays were scanned on a STORM 860 phosphorimager/fluorimager (Amersham Biosciences, UK). The resulting images were analyzed with the array vision software 8.0 rev 4 (Imaging Research Inc, Canada) and data from the duplicate spots were normalized using gene spring software version 5.0 (Silicon Genetics, USA) (13).

Two patients confirmed as having HPV18 infection by HPV gene array were used as the positive group, 13 patients infected with high-risk HPV as proved by the Hybrid Capture II system without HPV typing served as the mixed high-risk group, while five healthy women without HPV infection were the negative group.

IFN- $\gamma$ ELISPOT assays $(12,14)$. HPV18-specific T-cell responses were quantified by ELISPOT assay according to the manual of the human IFN- $\gamma$ ELISPOT kit (U-CyTech,

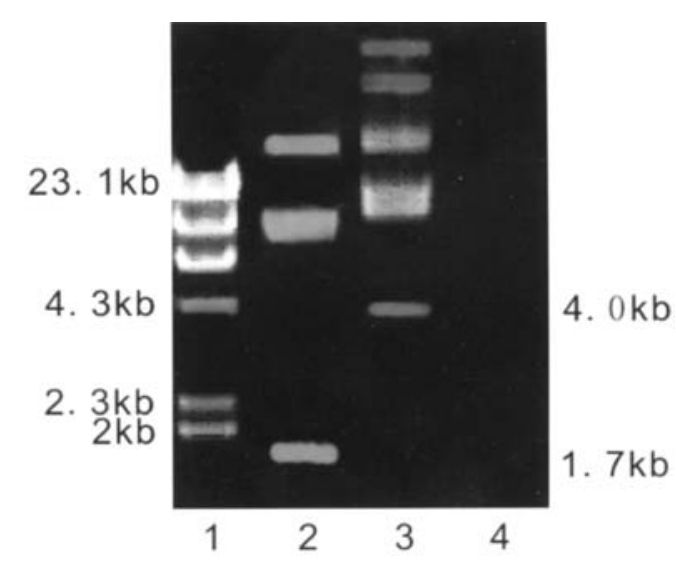

Figure 1. PCR analysis of the recombinant bacmid HPV18 L1. Lane 1: DNA marker; lane 2: bacmid-HPV18 L1 P3 viral stock-infected Sf-9 cells, the target fragments as long as $1.7 \mathrm{~kb}$ were obtained using the HPV18 L1 primers; lane 3: PCR products with the primers PUC/M13 corresponded to the size of the target gene $4.0 \mathrm{~kb}$, indicating that the transpositions were successful and lane 4: the negative control.

The Netherlands). Briefly, fresh PBMCs were plated onto 96-well plates that had been pre-coated with $0.5 \mathrm{~g}$ of antiIFN- $\gamma$ monoclonal antibody (BD Biosciences, USA). PBMCs were added at a concentration of $1,000,000$ cells per well in a volume of $100 \mu \mathrm{l}$ of Lympho-spot no-serum medium (U-CyTech) with antibiotics $(50 \mathrm{U} / \mathrm{ml}$ of penicillinstreptomycin). The concentration of the HPV18 L1 VLPs was $10-100 \mu \mathrm{g} / \mathrm{ml}$ in the Lympho-spot medium. Plates were incubated overnight at $37^{\circ} \mathrm{C}$ and $5 \% \mathrm{CO}_{2}$. The wells containing PBMCs alone in the Lympho-spot medium were used as negative controls. The wells containing PBMC and phorbol 12-myristate 13-acetate (PMA) served as positive controls. Triplicate experimental wells and quadruple control wells were used. The number of spots per well was counted using an automated ELISPOT plate reader (BioReader 4000, Germany), and the number of specific $\mathrm{T}$ cells was calculated by subtracting the negative control values.

Statistical analysis. Statistical analysis and graphical presentation were performed by SPSS13.0 and Sigma Plot 10.0. The results are given as the mean \pm standard error of the mean (SEM). Statistical analysis of significance was based on oneway ANOVA. $\mathrm{P}<0.05$ was considered statistically significant.

\section{Results}

PCR analysis of the recombinant bacmid. As shown in the Gene Bank, the standard length of HPV18 L1 (X05015) is $1,700 \mathrm{bp}$. Therefore, the PCR product produced by the pUC/ M13 primer should be 4,000 bp $(2,300$ plus 1,700$)$ if the construction was successful (7). Fig. 1 shows that a band of nearly 4,000 bp was found at lane 3 , proving the correct recombinant. Furthermore, 48-72 h after infection, the Sf-9 cells became rounder, swelled, had a stronger refraction than the uninfected cells and shed gradually. The Sf-9 cells were harvested, the cDNA was extracted and used as a PCR template, and then amplified with an HPV18 L1 gene-specific primer. The PCR product was $\sim 1,700$ bp the length of HPV18 


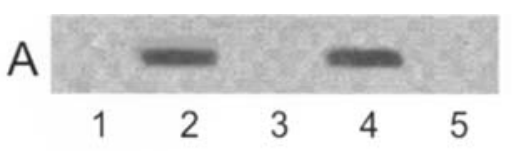

B

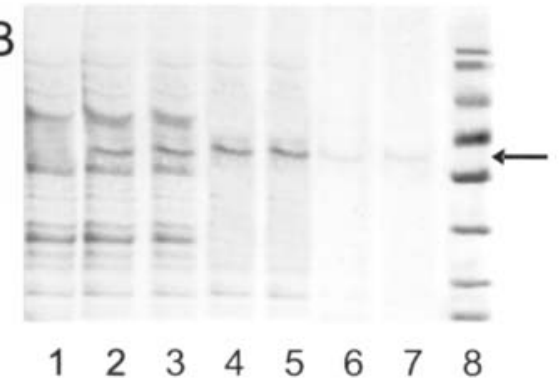

Figure 2. SDS-PAGE electrophoresis and Western blot analysis of the wildtype AcNPV- and recombinant AcHPV18Ll-infected Sf-9 cell lysates. (A) Western blot analysis using the anti-HPV-18 L1 monoclonal antibody. Lane 1: molecular weight reference (Mr) markers. Lane 2: the L1 band proved to be located around $63 \mathrm{kDa}$; lane 3: the wild-type AcNPV as negative controls; lane 4: the repeat sample of bacmid-HPV18 L1 (the same as lane 2) and lane 5: uninfected Sf-9 cells as the blank control. (B) Coomassie blue-stained SDSPAGE electrophoresis. Lane 1: uninfected Sf-9 cells as the blank control; lanes 2 and 3: the unpurified HPV18 L1 protein; lanes 4 and 5: the partly purified HPV18 L1; lanes 6 and 7: the purified HPV18 L1 protein under the native conditions and lane 8: (Mr) markers $(170,130,100,70,55,40,35$ and $25 \mathrm{kDa})$. The arrowhead on the right indicates the position of recombinant $\mathrm{L} 1$ $(-63 \mathrm{kDa})$.

L1 (lane 2). The above indicated that the infected Sf-9 cells contained recombinant bacmid including the HPV18 L1 gene.

Expression and purification of the recombinant $H P V-18 \mathrm{LI}$ protein. The Sf-9 cells were infected with high-titer recombinant baculoviruses, and $72 \mathrm{~h}$ later, the cell lysates were analyzed by SDS-PAGE electrophoresis and Western blot analysis. As shown in Fig. 2, SDS-PAGE electrophoresis demonstrated a novel $63-\mathrm{kDa}$ protein seen from the Coomassie blue staining in HPV18 L1-infected cells (Fig. 2B, lanes 2 and 3). This protein is not present in wild-type AcNPV lysates (Fig. 2B, lane 1). In Western blot analysis, a specific band reacted with a rabbit antiserum and against the linear HPV18 L1, antigen was found in the infected cells (Fig. 2A, lanes 2 and 4). The results proved that the HPV $18 \mathrm{~L} 1$ protein was expressed successfully and showed antigenicity.

A pure and simple $63-\mathrm{kDa}$ protein was tested by Coomassie blue staining after being purified by the Ni-NTA system (Fig. 2B, lanes 6 and 7).

Self-assembly of the HPV18 L1 proteins into VLPs observed with transmission electron microscopy (TEM). To determine whether the HPV18 L1 proteins derived from the infected Sf-9 cells have the capacity to efficiently self-assemble, lysates from the cells were analyzed by TEM. The Sf-9 cell monolayers fixed at $72 \mathrm{~h}$ post-infection showed distinct VLPs. No such structures were seen in the uninfected Sf-9 cells. Although the majority of the particles were identified in the nucleus of the cells (Fig. 3A and B), VLPs were also detected infrequently in the cytoplasm. The diameters of the VLPs were $\sim 55 \mathrm{~nm}$. This measurement is consistent with the diameter of isolated papillomavirus (15). The doughnut-like structures resembling the pentameric capsomeres of L1 were identified, as well as a variety of polymorphic capsomeric aggregates.

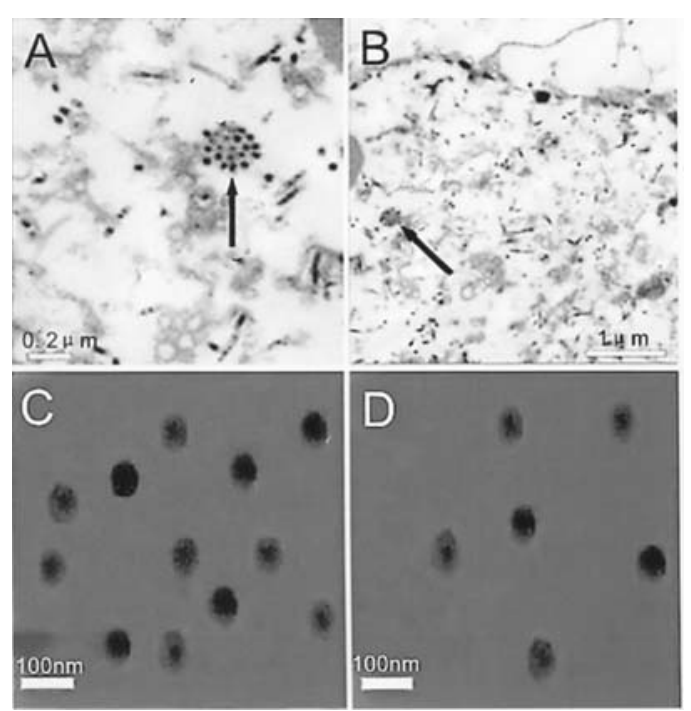

Figure 3. Electron micrograph of the HPV18 L1 VLP preparation shows selfassembly in vitro. (A and B) Electron micrograph of Sf-9 cells infected with AcHPV18 L1. SF-9 cells $72 \mathrm{~h}$ post-infection with capsid-like particles present in the nucleus. (C and D) Purified HPV18 L1 VLP particles. VLP particles purified from recombinant baculovirus-HPV18 L1 infected the insect cells with the Ni-NTA purified system on native condition. The bars in the A, B, C and D parts indicate lengths of 200,1000, 100 and $100 \mathrm{~nm}$, respectively.

These structures were distinguished from baculovirus inclusions seen in the cross-section in that the VLP arrays were not surrounded by a membrane-like structure and individual particles which had a greater diameter (16).

To prove the structure of the purified recombinant L1 proteins in vitro, the purified protein was prepared as previously described (8) and examined by TEM. Fig. 3C and $\mathrm{D}$ show the particles in detail.

All these results suggested that the HPV18 L1 protein can self-assemble into VLP-like structures successfully in vitro, which established the crucial basis for the development of the HPV18 vaccine.

Haemagglutination assay. The haemagglutination assay is regarded as a surrogate method of evaluating the capacity of antibody-mediated neutralization (9). To determine if HPV 18 L1 VLP-induced antibodies in the sera had a neutralizing capacity, haemagglutination assay was performed. Successful haemagglutination by VLPs was obtained from 50 to $400 \mathrm{ng}$ of pure VLP protein per $100 \mu 1$, suggesting that native and properly folded VLPs maintained antigenicity in vitro (Fig. 4).

IFN- $\gamma$ ELISPOT. Using HPV18 L1, VLPs pulsed the PBMCs in vitro with a concentration from $10,20,40,80$ to $100 \mu \mathrm{g} / \mathrm{ml}$. We evaluated the presence of a detectable immune response by determining the presence of IFN- $\gamma$-producing cells after VLPs and PBMCs were co-incubated for $36 \mathrm{~h}$ by means of the IFN- $\gamma$ ELISPOT. A significant difference occurred in the number of spot-forming CD8 ${ }^{+} \mathrm{T}$ cells (SFC: spot-forming cells) in response to HPV18 infected patients in a dosedependent manner. The average numbers of IFN- $\gamma$-secreting $\mathrm{T}$ cells of the wells in each group are listed in Table I in different VLP concentrations by the mean \pm standard error of the mean (SEM). As shown in Table I and Fig. 5D, the SFCs 
Table I. Analysis of HPV18-specific IFN- $\gamma$ secretion by means of the IFN- $\gamma$ ELISPOT assay.

\begin{tabular}{lrccccc}
\hline & & \multicolumn{5}{c}{$\begin{array}{c}\text { Mean no. of IFN- } \gamma \text {-positive T cells } / 10^{6} \text { PBMCs } \pm \text { SEM } \\
\text { for the VLP concentrations }(\mu \mathrm{g} / \mathrm{ml})\end{array}$} \\
\cline { 3 - 7 } Group & $\mathrm{N}$ & 10 & 20 & 40 & 80 & 100 \\
\hline HPV18 positive & 2 & $238.750 \pm 18.250$ & $309.250 \pm 4.750$ & $561.250 \pm 4.250$ & $794.750 \pm 33.250$ & $976.250 \pm 37.750$ \\
Mixed high-risk & 13 & $38.154 \pm 22.183$ & $59.885 \pm 33.988$ & $104.346 \pm 61.860$ & $117.154 \pm 67.544$ & $166.154 \pm 86.567$ \\
Negative & 5 & $3.500 \pm 1.012$ & $2.100 \pm 0.660$ & $1.700 \pm 0.752$ & $1.800 \pm 0.800$ & $0.900 \pm 0.292$ \\
P-values & & 0.002 & 0.008 & 0.006 & 0.001 & 0.001 \\
\hline
\end{tabular}

For each concentration, the difference of SFCs was analyzed by the one-way ANOVA test in each group and the level of SFCs was significantly different with $\mathrm{P}<0.05$. The P-values in Table I stand for the difference between the HPV18 positive group and the other two groups. SEM, standard error of the mean and $\mathrm{N}$, the number of patients in each group.

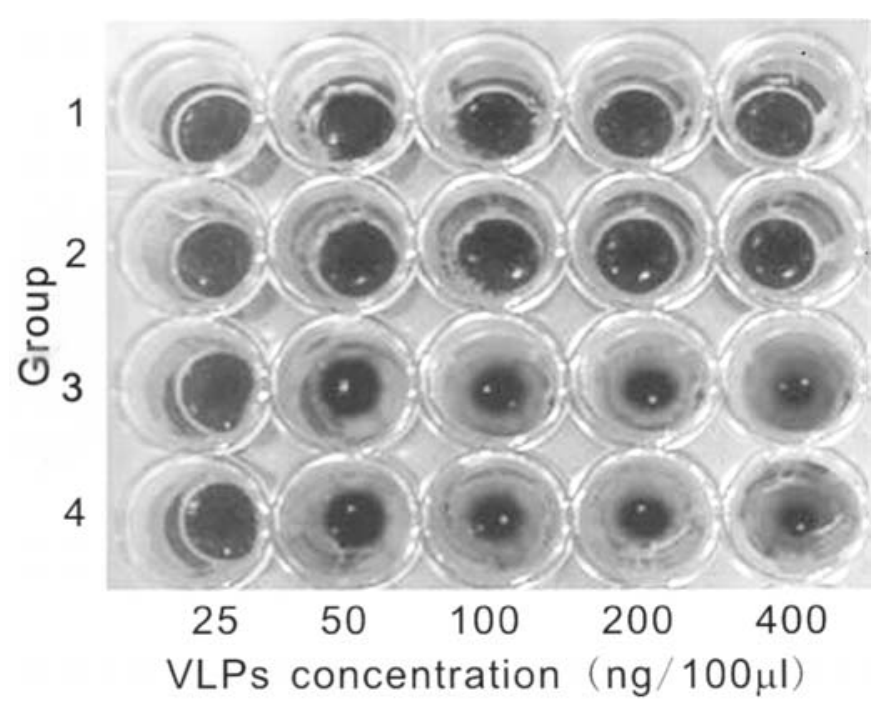

Figure 4. Result of the murine haemagglutination assay of the purified HPV18 L1 protein. Lane 1: blank control; lane 2: negative control; lanes 3 and 4: the purified HPV18 L1 protein co-incubation with murine haemagglutination at different concentrations.

per $10^{6}$ PBMCs in the HPV18 positive group with each VLP concentration were much greater in number than those in the mixed high-risk and negative groups, which had a high statistical significance $(\mathrm{P}<0.05)$. In the mixed high-risk group, fewer T-cell responses of IFN- $\gamma$ secretion were identified and nearly no responses in the negative group. This study showed that the purified HPV18 L1 VLP proteins may serve as targets for HPV18-specific CD8 ${ }^{+} \mathrm{T}$-cell responses. In the mixed high-risk group, fewer T-cell responses of IFN- $\gamma$ secretion were identified.

Fig. 5A, B and C shows a representative picture of each group on the ELISPOT plate. These results confirm that HPV18-specific $T$ cells can be sufficiently activated by purified HPV18 L1 VLP in vitro to a detectable level for analysis with an IFN- $\gamma$ ELISPOT assay.

\section{Discussion}

Globally, cervical cancer is the second most common cause of poor survival from cancer in women, with an estimated
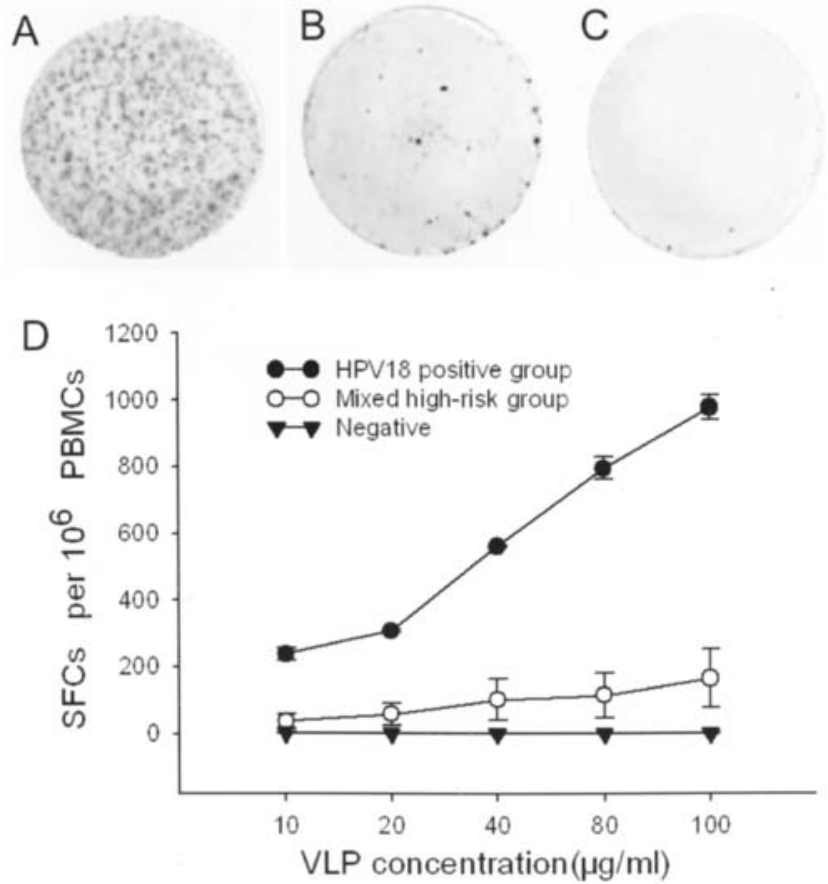

Figure 5. Representative presentation for each group in the IFN- $\gamma$ ELISPOT plate and the SFCs per $10^{6}$ PBMCs in each group with different VLP concentrations. (A) In the HPV18 positive group, many $\mathrm{CD}^{+} \mathrm{T}$ cells were stimulated with purified HPV18 L1 VLP and analyzed for antigen-specific IFN- $\gamma$ secretion by means of an IFN- $\gamma$ ELISPOT. (B) In the mixed high-risk group, there were fewer SFCs. (C) The negative group had nearly no reaction. (D) The SFC level in the HPV18 positive group was higher than that in the mixed high-risk group with different VLP concentrations. In the mixed highrisk and negative groups, the difference was also significant in each VLP concentration. There were nearly no SFCs in the negative group. SFCs: Spotforming cells.

510,000 newly diagnosed cervical cancer cases, counting for nearly $10 \%$ of all cancers (17). Furthermore, in developing countries, cervical cancer is often the most common cancer in women. Thus, cervical cancer is a critical public health problem and an overall disease burden for women throughout the world, especially in less developed countries. The fact that infection with certain HPV types is now recognized as a necessary intermediate step, the genesis of cervical cancer has led to new research fronts for the prevention of HPV- 
related diseases $(18,19)$. Research on the safety and efficacy of candidate prophylactic vaccines against HPV have shown very promising results with nearly $100 \%$ efficacy in preventing the development of persistent infections and cervical pre-cancerous lesions. The Gardasil vaccine produced by Merck that protects against the most common disease-causing HPV types (HPV6, 11, 16 and 18) was allowed to be used in clinical application by the American Food and Drug administration (FDA) in 2006 (20). In 2007, the American Cancer Society (ACS) developed guidelines for the use of the prophylactic quadravalence HPV vaccine. They address the use of prophylactic HPV vaccines, including who should be vaccinated and at what age, as well as a summary of policy and implementation issues (21). However, in developing countries, such as China, with their large populations suffering serious HPV infection, the economic burden has always been a central issue. Therefore, generating our own vaccine is essential.

In this study, we have shown that the L1 major capsid protein of HPV18 was expressed in the Bac to Bac baculovirus system efficiently and had a good bio-activity and immunity in vitro. In addition, it was proven with TEM that the purified recombinant L1 protein spontaneously assembled into a variety of aggregates, mainly particles with morphological characteristics in vitro similar to those of the VLPs. These observations confirmed that L1 has an intrinsic capacity for self-assembly and other papillomavirus proteins are not required for VLP formation in the baculovirus system (16).

Certainly, there are many kinds of HPV vaccines including protein, peptide, DNA and vector-based. We chose VLPbased vaccine, mainly because it is easy to produce on a large scale, is safe and highly immunogenic. As discussed previously, the L1 VLP is almost identical morphologically and antigenically to the infectious virus particle (22). Furthermore, we chose Bac to Bac baculovirus expression system for the following reasons: i) High levels of heterologous gene expression are often achieved compared to other eukaryotic expression systems, particularly for intracellular proteins. In many cases, the recombinant proteins are soluble, post-translationally modified and easily recovered from infected cells late in the infection when the host protein synthesis is diminished; ii) the cell lines used for the Autographa californica multiple nuclear polyhedrosis virus (AcMNPV) propagation grow well in suspension cultures, permitting the production of recombinant proteins in largescale bioreactors; iii) expression of the hetero-oligomeric protein complexes is achieved by simultaneously infecting cells with two or more viruses or by infecting cells with recombinant viruses containing two or more expression cassettes and iv) baculoviruses have a restricted host range, limited to specific invertebrate species. They are safer to work with than most other mammalian viruses since they are non-infectious to vertebrates (23).

In this investigation, we used the Ni-NTA purify system which is based on the theory that the 6xhis-tag in the $\mathrm{N}$ terminal of the proteins of interest can be bonded with the Ni-NTA resin, and then, eluted from the resin. Purified VLP was thus obtained without high centrifugalization and other traditional steps. This would be convenient and consistent with a large scale production.
Furthermore, others have reported that a successful immune response to genital HPV infections is characterised by strong, local cell-mediated immunity (CMI) that is associated with lesion regression and protection against further infection with the same genotype of HPV (24). However, few reports on HPV-specific cytotoxic lymphocyte (CTL) responses in humans have been published (25-27). In our investigation, we studied HPV18 CTL responses to test the VLPs immune reactions on patients, which would provide strong support for clinical use. As was reported (28), the T-cell-mediated protection from viral infection as well as control of the tumor is thought to be promoted by type 1 cytokine responses. In general, type 1 Th cells (CD4 or 8) which express IL-2, IFN- $\gamma$ and TNF- $\alpha / \beta$ are cytotoxic. However, type 2 Th cells express IL-4, -5, -6, -10 and -13, and provide efficient help for B-cell activation. Consistent with this view, IL-2- and IFN- $\gamma$-producing $\mathrm{T}$ cells are believed to promote the development of cell-mediated immunity against HPV-associated diseases. This study focused mainly on IFN- $\gamma$ producing in HPV18 VLPs induced immune response.

In this investigation, we showed efficient detection of HPV18-specific IFN- $\gamma$-producing autologous $\mathrm{T}$ cells after stimulations with HPV-18 L1 VLPs using an IFN- $\gamma$ ELISPOT assay (Fig. 5 and Table I). The ELISPOT assay is a recently developed technique for detecting cytokine expression at the single-cell level for special antigen-stimulated CD8 ${ }^{+} \mathrm{T}$ cells. Routinely used techniques such as ELISA and RT-PCR, do not provide information regarding the frequencies of cytokineproducing cells, in contrast to sensitive methods such as ELISPOT. We utilized ELISPOT immunological methods to quantitate the concentration of IFN- $\gamma$ and the number of IFN$\gamma$-secreting $\mathrm{T}$ lymphocytes in normal and HPV-infected populations (Fig. 5 and Table I).

The results of our investigation demonstrated that PBMCs pulsed with HPV18 VLPs were able to induce HPV18-specific cytotoxic CD8+ T-cell immune responses for HPV18-infected populations dose-dependently. In the mixed high-risk group without HPV typing, we also found that some immune responses occurred. It has been assumed that there are HPV18 positive patients in the mixed HPV infection group without HPV typing or, as discussed before, highly homologous VLPs such as HPV-6/11 (29), -31/33, -18/45 (30) and $-16 / 31$ (31) share one or more cross neutralization epitopes. Another hypothesis is that the cell-mediated immunity generated by L1 VLPs is cross-neutralising and not typespecific which is not the same as the immunodominant neutralising antibodies as the evidence showed before (30). In 2002, Combita et al (32) reported that the immunization of mice with HPV L1 VLPs indicated the existence of crossneutralization between types and cross-reactivity occurrence. They hypothesized that an HPV vaccine composed of the most frequent types (HPV16 and 18) also protected against related but less frequent types (HPV31, 33, 45 and 58). It is still uncertain whether this is sufficient to offer crossprotection in vivo. Therefore, further investigation is required. However, in the negative group, fewer reactions were detected. Our explanation is that, although uninfected populations had not previously been infected by HPV18, they were still able to generate HPV18-specific CTL 
responses from the endogenous $\mathrm{L} 1$-specific $\mathrm{CD}^{+} \mathrm{T}$ lymphocytes (28) or the non-specific reaction.

In general, there were more HPV18-specific CD8 ${ }^{+} \mathrm{T}$-cell precursors in the PBMCs of the HPV18 infected populations compared with the mixed high-risk and negative groups. These HPV-specific CD8 ${ }^{+}$T-cell precursors replicated and responded when they encountered the HPV L1 VLPs (28). A large case study will be needed to investigate this behavior in vitro and in vivo.

HPV18 VLPs may be used in a variety of ways to increase our understanding of HPV18 biology and mechanism. For example, they can be employed to study the HPV18 capsid formation, identify and characterize the HPV18 cell receptor and be considered as critical candidates for HPV18 vaccine development. HPV18 VLPs may provide abundant reagents with which to carry out immunologic and mechanism studies not only of cervical adenocarcinoma, but of other HPV-related diseases as well (16).

In conclusion, vaccination against HPV infection may reduce the risk thereof, thereby decreasing the incidence of cervical cancer. Our study on HPV18 VLPs provides a powerful foundation for the production of HPV18 vaccine and treatment of HPV18-related diseases.

\section{Acknowledgements}

This work was supported by grants from the National Science Foundation of China (No. 30371657 and 30170976) and the '973' Program of China (No. 2002CB513100). Appreciation is also extended to the guide and support given by the Wuhan Institute of Virology Chinese Academy of Sciences, China.

\section{References}

1. Kesic VB and Ostojic N: Etiopathogenesis of premalignant cervical conditions [in Serbian]. Abstract Book of Symposium of Premalignant Conditions and Cervical Cancer. pp21-30, 1996.

2. zur Hausen H: Papillomaviruses causing cancer: evasion from host-cell control in early events in carcinogenesis. J Natl Cancer Inst 92: 690-698, 2000.

3. Zhou J, Sun XY, Stenzel DJ and Frazer IH: Expression of vaccinia recombinant HPV 16 L 1 and L2 ORF proteins in epithelial cells is sufficient for assembly of HPV virion-like particles. Virology 185: 251-257, 1991.

4. Lowy DR and Schiller JT: Prophylactic human papillomavirus vaccines. J Clin Invest 116: 1167-1173, 2006.

5. Ferlay J, Bray F, Pisani P, et al: GLOBOCAN 2002: Cancer incidence, mortality and prevalence world wide [C] IARC Cancer Base No. 5, version 2.0. IARC Press, Lyon, 2004.

6. Belinson J, Qiao YL, Pretorius R, Zhang WH, Elson P, Li L, Pan QJ, Fischer C, Lorincz A and Zahniser D: Shanxi Province cervical cancer screening study: a cross-sectional comparative trial of multiple techniques to detect cervical neoplasia. Gynecol Oncol 84: 355, 2002.

7. Gibco B: Instruction manual of Bac-To-Bac baculovirus expression systems. Producer of Gibco BRL Products, 2004.

8. Montross L, Watkins S, Moreland RB, Mamon H, Caspar DL and Garcea RL: Nuclear assembly of polyomavirus capsids in insect cells expressing the major capsid protein VP1. J Virol 65: 4991-4998, 1991.

9. Roden RB, Hubbert NL, Kirnbauer R, Breitburd F, Lowy DR and Schiller JT: Papillomavirus L1 capsids agglutinate mouse erythrocytes through a proteinaceous receptor. J Virol 69: 5147-5151, 1995.

10. Reddy KJ, Banapour B, Anderson DE, Lee SH, Marquez JP, Carlos MP and Torres JV: Induction of immune responses against human papillomaviruses by hypervariable epitope constructs. Immunology 112: 321-327, 2004.

11. Sacerdote P, Rubboli F, Locatelli L, Ciciliato I, Mantegazza P and Panerai AE: Pharmacological modulation of neuropeptides in peripheral mononuclear cells. J Neuroimmunol 32: 35-41, 1991.

12. Liu HW, Hong KX, Ma J, Yuan L, Liu S, Chen JP, Zhang YZ, Ruan YH, Xu JQ and Shao YM: Identification of HIV-1 specific $\mathrm{T}$ lymphocyte responses in highly exposed persistently seronegative Chinese. Chin Med J 119: 1616-1621, 2006.

13. Vazquez-Ortiz G, Ciudad CJ, Pina P, Vazquez K, Hidalgo A, Alatorre B, Garcia JA, Salamanca F, Peralta-Rodriguez R, Rangel A and Salcedo M: Gene identification by cDNA arrays in HPV-positive cervical cancer. Arch Med Res 36: 448-458, 2005.

14. Cools N, Ponsaerts P, Lenjou M, Nijs G, Van Bockstaele DR, Van Tendeloo VF and Berneman ZN: Sensitive detection of human papillomavirus type 16 E7-specific T cells by ELISPOT after multiple in vitro stimulations of CD8+ T cells with peptidepulsed autologous dendritic cells. Mol Cancer 5: 49, 2006.

15. Klug A and Finch JT: Structure of viruses of the papillomapolyoma type. I. Human wart virus. J Mol Biol 11: 403-423, 1965.

16. Rose RC, Bonnez W, Reichman RC and Garcea RL: Expression of human papillomavirus type $11 \mathrm{~L} 1$ protein in insect cells: in vivo and in vitro assembly of virus-like particles. J Virol 67: 1936-1944, 1993

17. Pagliusi S: Human papillomavirus infection and cervical cancer. World Health Organization http://www.who.int/vaccine_ research/diseases/hpv/en/.2006, October 26.

18. Franco EL, Rohan TE and Villa LL: Epidemiologic evidence and human papillomavirus infection as a necessary cause of cervical cancer. J Natl Cancer Inst 91: 506-511, 1999.

19. Bosch F, Lorincz A, Muñoz N, Meijer C and Shah K: The causal relation between human papillomavirus and cervical cancer. J Clin Pathol 55: 244-265, 2002.

20. Villa LL: Prophylactic HPV vaccines: reducing the burden of HPV-related diseases. Vaccine 24: S23-S28, 2006.

21. Saslow D, Castle PE, Cox JT, Davey DD, Einstein MH, Ferris DG, Goldie SJ, Harper DM, Kinney W, Moscicki AB, Noller KL, Wheeler CM, Ades T, Andrews KS, Doroshenk MK, Kahn KG, Schmidt C, Shafey O, Smith RA, Partridge EE, Gynecologic Cancer Advisory Group and Garcia F: American Cancer Society Guideline for human papillomavirus (HPV) vaccine use to prevent cervical cancer and its precursors. CA Cancer J Clin 57: 7-28, 2007.

22. Trus BL, Roden RB, Greenstone HL, Vrhel M, Schiller JT and Booy FP: Novel structural features of bovine papillomavirus capsid revealed by a three-dimensional reconstruction to $9 \mathrm{~A}$ resolution. Nat Struct Biol 4: 413-420, 1997.

23. O'Reilly DR: Use of baculovirus expression vectors. Methods Mol Biol 62: 235-246, 1997.

24. Stanley M, Lowy DR and Frazer I: Chapter 12: Prophylactic HPV vaccines: Underlying mechanisms. Vaccine 24: S106-S113, 2006.

25. Cheng WF, Hung CF, Hsu KF, Chai CY, He L, Polo JM, Slater LA, Ling M and Wu TC: Cancer immunotherapy using Sindbis virus replicon particles encoding a VP22-antigen fusion. Hum Gene Ther 13: 553-568, 2002.

26. Cheng WF, Hung CF, Chai CY, Hsu KF, He L, Rice CM, Ling M and Wu TC: Enhancement of Sindbis virus self-replicating RNA vaccine potency by linkage of Mycobacterium tuberculosis heat shock protein 70 gene to an antigen gene. J Immunol 166 : 6218-6226, 2001.

27. Cheng WF, Hung CH, Chai CY, Hsu KF, He L, Ling M and Wu TC: Enhancement of sindbis virus self-replicating RNA vaccine potency by linkage of herpes simplex virus type 1 VP22 protein to antigen. J Virol 75: 2368-2376, 2001

28. Cheng WF, Lee CN, Su YN, Chang MC, Hsiao WC, Chen CA and Hsieh CY: Induction of human papillomavirus type 16specific immunologic responses in a normal and an human papillomavirus-infected populations. Immunology 115: 136-149, 2005.

29. Orozco JJ, Carter JJ, Koutsky LA and Galloway DA: Humoral immune response recognizes a complex set of epitopes on human papillomavirus type 611 capsomers. J Virol 79: 9503-9514, 2005.

30. Giroglou T, Sapp M, Lane C, Fligge C, Christensen ND, Streeck RE and Rose RC: Immunological analyses of human papillomavirus capsids. Vaccine 19: 1783-1793, 2001.

31. Fleury MJ, Touze A, Alvarez E, Carpentier G, Clavel C, Vautherot JF and Coursaget P: Identification of type-specific and cross-reactive neutralizing conformational epitopes on the major capsid protein of human papillomavirus type 31 . Arch Virol 151: 1511-1523, 2006.

32. Combita AL, Touzé A, Bousarghin L, Christensen ND and Coursaget P: Identification of two cross-neutralizing linear epitopes within the L1 major capsid protein of human papillomaviruses. J Virol 76: 6480-6486, 2002. 